ideas. Probably the most trenchant and impressive essay is the one contributed by Bolton Hall on charity. Several of our conservative notions anent philanthropy receive quite a jolt, even though we refuse to follow the writer to the ultimate acceptance of his own ideals. Mr. Fillebrown of Boston writes in his usual terse way on equal rights to land. Several others possess the real merit of logic made convincingly interesting. But as in much of their literature, the single taxers are here prone to wearisome prolixity and overfond of referring to Progress and Poverty as a veritable Koran-thereby creating doubt in some minds as to their individual originality or ability to do their own thinking. But to those who know only the "dangerous little" about the single tax doctrine, a dip into this little volume will do no harm-except to the eyes; the typography leaves a good deal to be desired.

Philadelphia.

A Political Primer for the NeW Voter. By Bessie Beatty. San Francisco: Whitaker and Ray-Wiggin Company, 1912, pp. 76.

The title of Miss Beatty's little book should give a fair guess at its purpose. But from the introduction it appears that it is intended as a textbook in elementary schools as well as a handbook for the new voter. It is, however, suited neither to school child nor new voter-least of all to the new voter who is foreign born. It is far from being simple enough for its proposed students and readers. Phrases like "the destruction of party autocracy" abound. "Reconstruction," "public service corporations," and the like are without definition or explanation. It is in many cases inaccurate, carelessly written and printed. The sketch of the history and policies of the Democratic and Republican parties is not sufficiently adequate to be informing for its declared purpose. And there is the handicap for wide use that nearly all the illustrative examples of the workings of our state governments are taken from California. The book is thus to a large extent a description of conditions existing in that state, often existing in that state alone.

But this primer still has distinct value, a value that is in part suggestive. There has long been need of an elemental book of civics, brightly and interestingly written, as is this, but also very carefully and very simply written, prepared with a clear knowledge of what our American boys and girls need to know, of whatand this should be a separate book-our foreign born new citizens and prospective citizens need to know of our political life and government and of their civic duties.

There is a further virtue in this primer. The spirit of the book is admirable, broadly patriotic with a very persuasive enthusiasm for every good cause, marking a wide difference from the dull and stereotyped books of civics that have too long been imposed on our young people. The chapters on socialism and the legal status of women are excellent. So, too, is the account of California's recent legislation, its progressive achievements and program.

\section{New York.}

\section{John Fostmr Carr.}

The Municipal Year Book of tere United Kingdom For 1913. Founder and Director, Robert Donald; Editor, Albert E. Cave. London: The Municipal Journal, Ltd. 15 shillings,

The present volume contains 1150 pages as compared with 1131 in the 1912 volume. It is divided into 28 sections and besides giving information concerning the local government board and municipal corporations in England, Wales, Scotland and Ireland, it contains full information about the London government and urban district councils. Then there are a number of sections devoted to specific topics like housing, markets, baths, free public libraries and public cemeteries. The section on town planning has been entirely rewritten and constitutes a short treatise on the prac- 